\title{
From shamanism to the space age: reconciling with ancient beliefs may prepare us for Contact
}

\author{
John F. Caddy PhD
}

\begin{abstract}
SUMMARY:- A lifetime's work in applied marine ecology convinced me that trying to conserve wild populations by 'Scientific Resource Management' is often unsuccessful. Rather than a technical deficiency, this seems to stem from modern society's lack of an ethical context for conserving 'Mother Nature'. A higher priority is placed on the economic value of a resource than preserving its role in the ecosystem. This deficiency didn't apply to the ancient belief system of Animism, which saw Mother Nature as 'The Great Spirit' and the landscape and its ecosystem as Her expression. The old idea that Nature is feminine persisted until roughly 100 years ago, and much further back, links us to an ancient view of life prior to Monotheism. We rarely refer nowadays to 'Mother Nature' as the guiding spirit for events on this planet, although close analysis shows that we have scant control over them: 'She' is still in charge. Hence, reviving a belief in the unitary spirit of nature on this planet and elsewhere, should be a guide for conservationists. The ancient counterpart to Mother Nature is James Lovelock's Gaia; our local planetary 'super-organism' - again, a huge female entity who commands little media attention while we disrupt world ecosystems in the name of profit. The change in our way of thinking that will probably follow from contact with extraterrestrial civilizations will be even more traumatic than the shift in Celtic countries from shamanic/Animistic beliefs to Christianity, documented by Evans Wentz (1911) and Dames (1992), which is offered for comparison. It is speculated that a neo-shamanic approach sensitive to vital energy and aware of other planes of reality, may be easier to reconcile with successful modes of perception and communication with extraterrestrial species than a materialistic viewpoint.
\end{abstract}

\section{INTRODUCTION}

This paper should be seen as a reflection of my personal views on reality, and is an attempt to address an important question: are we approaching unprepared a major decision point in our history, as authors such a John Sutcliffe have suggested? I should explain my background first. Apart from my enthusiasm for ecology, in the 1980's and 90's my spare time was spent learning about 'vital energy' and how to detect it. This was independent of my professional work in resource management, but made me reflect on the many failures I have observed in my technical field. These occurred largely because managing fish stocks was seen as a practical issue, with no spiritual consequences of failure perceived. The practical disciplines of shamanism and pranic healing taught me to sense qi - otherwise known as the 'life force', 'orgone', or 'subtle energy' - a few of the names esoteric schools use for vital energy. Qi or Chi, can be detected in auras and chakras, and in nature; including sky and ground energies implicit in the Chinese concept of Tao - itself a relict, I suppose of early shamanic beliefs. I described learning to detect qi in 'A Return to Subjectivity', and as a result, underwent a personal paradigm change in my view of 'objective reality'. Since then I have been trying to integrate archaic revelations into my scientific view of the world. I've come to see the dichotomy between Science and the Spirit as a dangerous form of social schizophrenia: on the one hand, the spiritual significance of recent scientific discoveries has been neglected, but we also need to reinterpret religious revelations within an expanded cosmology, in which ancient practices and the recent discoveries of science should both play a role. One way of visualizing qi I find useful in evolutionary theory, is to take the common origin of biosphere components into account. This suggests we should see qi as a mechanism for exchanging information and vital energy between the vastly diverse units surviving from the original 'Big Birth': our brothers and sisters in the global ecosystem. It would not be surprising if this living energy could be picked up by the offspring of that moment of creation, and not by non-living devices.

Three wider perspectives on this common origin and potential union may be useful:

1) The 'Big Bang' and the multiple dimensions postulated in 'Theories of Everything' are not just science but spiritual revelations - although not incorporated yet into religious credos. The common origins of all planetary life forms (the 'Big Birth') was revealed by genetics and is also a spiritual revelation, as is Gaia - the aura of all living organisms.

2) Most religious traditions see the soul as an 'immaterial element' coming from, and returning to, another realm of reality. This should be compatible with the common origin of life forms, as well as Multiverse theory. A 
biologist might even describe interactions between the physical body and an 'energy body' coming from another realm, as 'trans-dimensional symbiosis'.

3) From personal experiences with dowsing the language of emotions and the scientific vocabulary, the procedures of Science, or 'objective investigation', have to be expressed in a vocabulary low in emotional energy (the 'Band of Rationality'; Caddy 2011). Science requires controlled scepticism, however, so-called 'independent observers' can collapse the qi field needed for the manifestation of paranormal phenomena. Such manifestations are associated with high spiritual energy and cooperating minds.

\section{Defining the scientific problem in its spiritual context}

Much published output in the controversial field of vital energy, directly or indirectly, concerns the 'chasm' between Science and Religion/Spiritual traditions. The usual approach is to try to reconcile Scientific Materialism and Monotheism, but these make uneasy bedfellows due to differences in their paradigms and basic dogmas respectively. However, the belief in a single Deity is compatible with the idea of a 'Prime Mover' and this could be argued as the logical basis for a 'Theory Of (Nearly) Everything' or 'TONE' (Caddy 2007) that includes spirituality as well as guidance in the practical issues of life. It is the best personal source we can achieve given the large gaps in our knowledge, both practical and spiritual.

The Holy Books of monotheistic religions offer 'Theories of Origin' as an incontrovertible truth. Since Science has little other than speculation to explain what happened before the Big Bang, the contrast between Religion and Science in interpreting 'The Time before the Origin of the Universe' is not such a radical one. Some religious denominations have accommodated to the Big Bang theory, and at least tacitly, to other scientific discoveries since the Middle Ages. Unfortunately, some have refused the concept of Darwinian evolution which to me is a logical and inevitable consequence of errors in duplication occurring during the passage of time.

In fact, after the 'Galileo case', the Church appeared to relax its conflict with Science, and took into account the principle of cause and effect which led to Newtonian physics and scientific cosmologies. This 'truce' between a monotheistic religion and science, was favoured by the early Church adopting interpretations of the profane world postulated by Aristotle and other pre-Christian Greek sages on matter and physical energy. Perhaps in reaction, the early Church reinforced the division between the realm where Science applies, and that of the Spirit, by emphasizing the importance of Faith. In Europe at least, science grew alongside official State religions in an uneasy coexistence, until recently when questions of contraception, abortion and stem cell research have become sources of controversy. Attempts to bridge the gap between Science and Faith have not been explicitly encouraged by some monotheistic religions, but others, for example, the Dalai Lama for Tibetan Buddhism, has urged the recognition of scientifically incontrovertible truths by religion. The acid test for human religions in the not-too-distant future, will be how they integrate their ideas of the Deity with those of more intelligent species - supposing that when the extraterrestrials arrive, they will have similar concepts?

\section{Integrating the ecosystem into religions?}

It is my contention that it would be more useful for Science to avoid focussing on the contrast between monotheistic dogmas and Science 'facts' and theory, and for religious persuasions to focus more attention on the conservation of our precious ecosystems, the so-called inanimate aspects of creation, and how the existence of other highly intelligent species should affect our belief systems. It would be particularly useful during this time of degradation of our planetary ecosystems, for us to focus on an investigation of earlier Animistic beliefs, which ascribed a spiritual reality to both the 'animate' and 'inanimate world'. The beliefs of Animism stemmed less from theory, and more from millennia of shamanic practice and enhanced sensibility. Thus, they originated not from any logic of primary causes, but more from the perceptive power of those who lived enfolded in the ecosystem and close to the land over millennia. The recent encyclical by Pope Francis suggests that the Catholic Church has begun recognizing the importance of conserving our physical habitat and our companion species in evolution, as well as the condition of the human soul. It is written, "The Earth is protesting for the wrong that we are doing to her, because of the irresponsible use and abuse of the goods that God has placed on her. We have grown up thinking that we were her owners and dominators, authorised to loot her. The violence that exists in the human heart, wounded by sin, is also manifest in the symptoms of illness that we see in the Earth, the water, the air and in living things."

This view must be welcomed by ecologists, although the use of the word 'goods' implies inanimate and animate entities are intended principally as benefits for our species. It differs from the Animist interpretation, where even the physical structure of the earth as well as its human and animal inhabitants are charged with vital energy. Nevertheless, it does represent an understanding of the importance of ecosystems of which we are a vital part, for the continuity of human life on earth. 


\section{The role of religion for our distant ancestors and for rural populations}

In my ignorance, I would nonetheless assert that rural peoples, past and present, who live in close contact with Nature, were less dominated by their frontal lobes and left brain activities than modern city dwellers. It seems they gave more credibility to non-ordinary phenomena than science does, even if their beliefs are expressed in traditional perceptions and explanations. The relationship between these perceptions and their possible underlying scientific explanations, merits further discussion, and was one of the motivations for my book 'A Return to Subjectivity'.

With this idea in mind, I want to discuss a well-documented example: the pre-Christian beliefs of Celtic peoples as described in the book 'The Fairy Faith in Celtic Countries' by Evans Wentz (1911). This remarkable text was based on interviews 'in the field' during the first decades of the $20^{\text {th }}$ Century. Supplemented by Michael Dames, (1996), it documents experiences and beliefs of rural folk of Celtic origin in Scotland, Ireland, Wales and Brittany with regard to those supernatural beings, nowadays scoffingly placed in the category of fairies, but more accurately referred to by the ancient Irish as 'The Sidhe', whose characteristics and activities resemble those described recently for extra-terrestrials. As Evans Wentz noted, "beliefs in supernatural beings find their parallels the world over". In the $19^{\text {th }} \mathrm{C}$ and earlier, superstitions in rural areas of Europe were beginning to be replaced by materialistic/rational thought processes with the onset of modern systems of education. As such, the Evans Wentz study gives us a rare glimpse backwards to the millennial traditions that preceded Christianity in Western Europe.

Although early beliefs may be considered irrelevant in the modern world, a close analogy exists between the non-human entities described in Celtic mythologies and current preoccupations with UFO phenomena. This is remarkable, and makes one wonder whether the religious entities bringing 'revelations' as described in some religious traditions, in fact reflected visits by off-planet entities? As already noted, the Sidhe were of several distinct types; for example, shining entities and opalescent ones. One peasant reported that: 'In seeing these beings of which I speak, the physical eyes may be open or closed. In their own world and nature" (the Sidhe) "are never seen with the physical eyes". This correspondent described two Sidhe races belonging to two other worlds than ours: "Those which are shining" (at about our own stature, belonging to the mid-world), "and those which are opalescent and seem lit up by a light within themselves" (much taller than ourselves, belonging to the upper world). He reported that these shining beings lack individuality, and move together in response to a higher being than themselves. Despite their apparent purity and exaltation, they live a collective life without individual volition: the analogy was made to a hive of bees (or as we would assert nowadays, to identical cloned organisms?). The opalescent beings also have close spiritual unity, but more individuality. Other forms, often much smaller, were associated with woods and waters, and appeared identical with what were called 'elementals' or nature spirits by mediaeval scholars. Their names are well known in children's stories, but will not be used here to avoid obscuring the analogies. Evans Wentz considered these 'races' as "neither divine nor human", but existing on a separate plane; "occupying the same space" as ours, which he referred to as an 'Astral' plane. This resonates in its remarkable similarity to descriptions of hallucinogenic experiences with dimethyltryptamine, in which subjects described interacting with 'machine elves' in spaceships (Strassman 2001).

Recent opinions have been expressed in the media that early 'belief systems' have much in common with UFO phenomenology. Following up on their commonalities may even allow creative hypotheses to be extended backwards in time to a history of 'alien' contacts which influenced the early development of spirituality in our species. A favourite topic on the Web is that the intelligence of our species benefitted from long-past interventions on our ancestral primate species by extraterrestrials, perhaps as workers to help them construct pyramids and early cyclopean structures history has not yet found a place for? Celtic sources also seem to support the idea that we are dealing here with trans-dimensional visitations by aliens. This is an alternative to the hypothesis of 'Spaceships making the long journey in conventional space-time from Alpha Centauri', which is the only centuries-long option possible under Einstein's theory of relativity. The growing realization now is that we are being regularly visited by a number of species from other star systems using alternative shorter modes of travel, as yet beyond our scientific comprehension. These beings probably have a much longer evolutionary history and superior intelligence than we do, and may have much to teach us technologically, but possibly also spiritually, as described by Steven Greer (1999, 2006).

This is not the place to discuss in detail the growing suspicion voiced on the Web, that at least since the 1950 's, some governments, transnational corporations and the media, have sought to implement a global ban on public information concerning 'flying saucers' and their inmates. The attempt to mislead seems less intensive nowadays. Recently I had the opportunity to see these vehicles in person, hence this section of the report is not hypothetical for me! Given that extraterrestrial civilizations are now for me a reality, it seems probable that within the next century, the current view will change as information is 'leaked' through the Web to the public. In 'Disclosure': a public policy discussing how the state of affairs in human-extraterrestrial relationships should change, Steven Greer suggests that when their technology of extracting clean energy from the vacuum used by 
our visitors is allowed to be implemented on Earth, it will bring to an end to the dirty Age of Carbon. This will transform our ability to build a clean technology, but our sensibilities, spiritual beliefs, and religious and geographical limitations, will presumably also change? One prediction that seems to emerge from the uncertain information available, is that a closer merging of Science and Spirituality is likely, which is one of the objectives of this paper. A growing tide of unofficial internet communications recently suggested that our future visitors, unconstrained by Einstein's theories, are capable of trans-dimensional travel from vast distances by extracting energy from the framework of space and using 'wormholes' between different spatial branes to shorten their voyages. According to Steven Greer, they implement distant communication by a combination of what we might call spirituality and technology; namely enhanced telepathic communication. The idea that there is a single Cosmic Mind also emerges, of which we and all other intelligent species in the Cosmos form part. This itself, can be seen as an interstellar outgrowth of our terrestrial phenomenon, Gaia. She is postulated to exist on a much smaller scale on this planet, aided by the impressive diversification of earth-bound species coming from a common origin. All of the above might be regarded as outrageous speculation by an earlier generation: it does however suggest an explanation of how Science and Spirituality, together, may lead to extraordinary discoveries.

There may be 'rational' reasons why perceptions of qi have become less evident in this materialistic age. According to Marshall McLuhan (1994) a change in the medium of communication IS the message, and we see that the recent conquest of global information transmission by the Internet has radically changed communication internationally. While this makes it virtually impossible to keep secrets from the public, it also makes it largely impossible to separate facts from speculation or fantasy. One other important point is that this technological advance makes the world's secrets available to the poor via cheap portable telephones, but also potentially allows their views to be heard. For Evans Wentz and Dames, an older 'transference' of belief between pre-Christian deities such as the goddess Brigit and her re-naming as the Christian Saint Bridget occurred in Ireland. This was an early example of how changing basic beliefs changes our mode of perception. In early Irish history, the transfer of place-events characterised by pagan folk heroes, (e.g. the Celtic god Bran), and their later re-identification at the many locations in rural Ireland Saint Patrick supposedly visited during his time there, seems to have been the mechanism for switching the basic axioms of life. The strategy implied by the renaming of the same pagan sites and the transfer of rural populations to a Christian mythology is now apparent. This was achieved without notable strife and is graphically described in the Icelandic Sagas, so that the old traditions were submerged but now live in the subconscious. As a result, the names have been changed, but the sacredness of the local sites continue to be recognized. Similar situations appear to have developed in Mayan and post-Incan contexts, where pagan themes were absorbed into pre-Christian ceremonies (or vice versa) by 'Superpositioning'. This term used by Dames (1992) refers to the coexistence of two spiritual realities where the membrane between two planes of reality is thinner. This process seems to favour a peaceful transition in belief systems.

In her foreword to the 1977 edition of Evans Wentz's book, Kathleen Raine described the earlier Celtic belief system as a 'doctrine of souls' involving the interrelationship of two worlds; the material world, and from Celtic experience, a second realm that interpenetrates this one. "On death we enter their world; and by implication, they, at birth, enter ours". Here we have an example of a belief system in which an alternative plane of being is visualized, with specific properties that are not overtly spiritual, but imply that activities carried out in the physical world also occur on another plane. Ordinary human profane motivations on this alternative plane are evident in a way that echoes the words of Hermes Trisigeminus; "As above, so below". In other words, it would be more reasonable to compare the pre-Christian Celtic cosmology with the predictions of (say) a multidimensional String Theory, than to compare it with Heaven and Hell; the spiritual locations postulated by monotheism: sites supposedly inhabited exclusively by either Good or Bad souls. Raine expressed the hope that Evans Wentz's work would lead to "A science of souls...to supersede the prevalent materialist science which recognizes only bodies".

While this may be an optimistic view, from personal experience with non-ordinary disciplines I believe that pre-Christian beliefs and more specifically, what is called Animism, routinely incorporated experiences and perceptions of paranormal phenomena within a spiritually-charged landscape, rather than depending largely on dogma and sacred mythologies. The 'Land' itself was sacred in older religious traditions, and imbued with spiritual significance. This was also documented for Australian aborigines by the popular work of Bruce Chatwin (1988), and by anthropologists. The relationship of hunter-gatherer societies to the natural world was one which incorporated an intimate knowledge of local landscapes and their psychic properties on the part of hunter-gatherers and pastoralists. Sacred sites were sought that were energetically resonant, apparently in part because they overlay underground water. The early churches in Europe, were often constructed on such formerly pagan ceremonial sites. This was documented by Alfred Watkins (1925), who showed that so-called 'ley lines' linked earlier sacred sites, whether or not these are now marked by modern structures. Monotheistic 
credos promoted there basically relied on the ability of our pagan ancestors to sense strong psi phenomena in the surrounding environment.

\section{The role of priesthoods}

Until recent times, our communication with the world of the spirit relied on mediation by a priestly cast, where formerly this was between individuals and the spirit world in a more direct sense. In the European Middle Ages, personal research into phenomena that we might call 'spiritual' was actively discouraged by monotheism, using the criteria spelled out by the Inquisition. My personal experience in Ireland has convinced me of the reality of this kind of direct vision, and its linkage to a landscape where traditional belief systems have not been destroyed by 'materialistic thought'.

Evans Wentz also reported observations from educated persons living in the Irish countryside in the 1930's, that the 'water beings' are "kept alive by something akin to electrical fluids". The higher orders "seemed to me to draw their life out of the Soul of the World". These entities had a strong aura, and a way of describing this feature is that pre-Christian encounters with spiritual entities occurred in 'druidical mists'. My interpretation of this last phenomenon is similar to that described by Castaneda as 'the lines of the world', and by $19^{\text {th }}$ century spiritualists as 'ectoplasm': i.e., it is what can be perceived when a concentration of chi or prana makes visible the membrane separating planes of reality. Perhaps this could be a manifestation of the fractal dimensions which occur at the boundary between different planes of reality (see Mandelbrot 1977).

\section{The passage of time}

Celtic traditions (as with the ancient Teutonic story of Rumpelstilzchen), suggest that in the "parallel worlds' contacted by our ancestors, time proceeds at a different rate than in ours, and seasons may also be out of step. Persistent myths of several European peoples recount that as soon as the time traveller leapt out of his coracle, and placed foot to ground on returning from a short stay in another realm, he aged instantly; "forthwith he was a heap of ashes, as though he had been in the earth for many hundreds of years". This mythical occurrence, described by the companions of Bran the Irish hero, is intuitively reasonable and consistent with Celtic experience, but interpreted logically, suggests that the two realms are superimposed spatially. However, time passes in that other realm 'at an angle' to the flow of time in ours, such that the rate of development of events in the two different realms are out of step - perhaps another reason why long distant travel can be accomplished in a short subjective time in other realms? An analogous explanation for the visits of extraterrestrials (if one can be offered), is not that we are discussing trans-stellar flight to and back from a distant planet at relativistic velocities, but rather a much shorter voyage via a parallel plane of reality? Certainly for diehard materialists, the basic explanation is that UFOs are illusions. Alternatively, the comforting thought is held in mind that they are unable to reach us through ordinary space from 'beyond Alpha Centauri'; given the many light years distance as the limiting factor.

A commonly reported Celtic mythology concerned the prohibition by the inhabitants of the other world that their activities be observed by humans. Those few humans able to observe the Sidhe, once their capability was detected by the elves, it was rapidly corrected, or they were abducted to 'fairyland'. Evans Wentz cited several examples of this type of intervention by the Sidhe. One could postulate that a similar motivation stems from our uneven ability to detect extraterrestrial beings, and modern reports describe abduction and subsequent surgical operations by extraterrestrials on those able to sense them: a comparable phenomenon in the Celtic world was the substitution of ugly 'changelings' for the newborn by fairies. By now thousands of modern abductions have been reported, not all of which seem to be fantasies.

\section{Personal experiences}

From my own experience I contend that there are still strange phenomena to be encountered at specific landscape sites which have remained unchanged and respected by local peoples, and where traditional beliefs have not been completely abandoned. Phenomena encountered by the author in a visit to Ireland in 2004 led to several perceptions of what appeared to be 'mythical fairy creatures' by myself and others in an altered state taught by Ken Eaglefeather (1995) as 'Dreaming Awake'. This altered state may be described as 'living outside your head', which I believe involves perceiving phenomena directly through the lower chakras. My interpretation of these states of perception is that they allow access to phenomena implicit in the vital energy nexus (Gaia's aura) that surrounds this planet, and can be detected through the lower chakras. Two examples seen in the Ring of Kerry, Ireland, where I was able to make a rough sketch of visions, are shown below: The first seemed to me to be an induced imagery of a psychic barrier, designed to warn unwanted visitors to leave Ireland: 

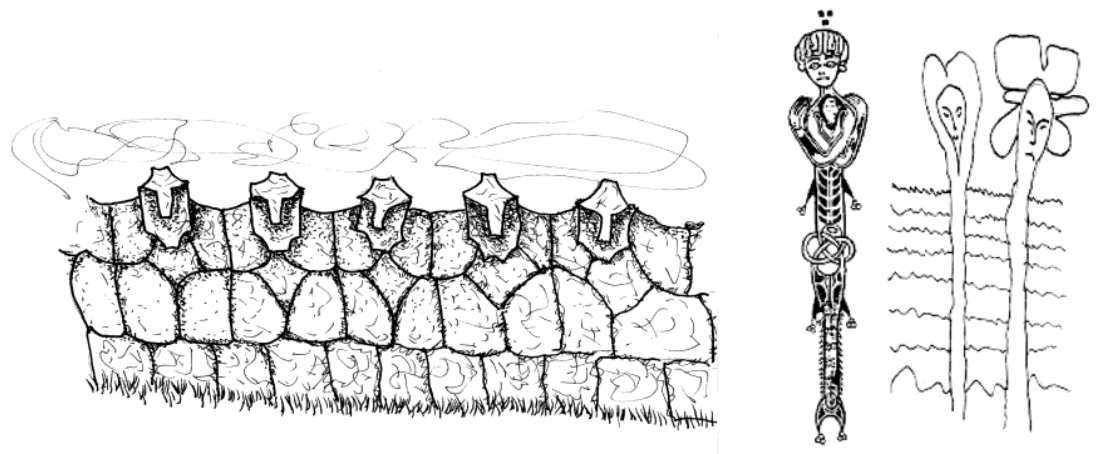

The second of a 'mermaid', sketched while sitting at the seaside, is compared with a drawing (left) from the $10^{\text {th }}$ Century book of Kells (prepared by 'monks' with memories of the ancient religion?) I saw in the museum in Dublin.

As I interpret it, these non-ordinary states of perception can best be explained using the theory of chakras. Indian yogic practice regards these 7 principal vortices in the energy body essentially as 'portals' to different states of reality. I have found on rare occasions that it is possible in unusual 'mental' states to 'see' through them. ('Mental' is not the correct word, since mind is associated with the brain, and this form of perception seems to allow communication with a 'plane of reality' accessible only through the lower chakras and associated neural complexes of the body). It seems to me useful to note assertions that the Ancients were better able to use this perceptual modality than modern man. 'Energetic' experiences in areas where mythical events supposedly occurred, may involve 'sensitives' accessing standing vibrations or resonant structures left by repetitive ceremonies at points in the landscape where vital energy fields are strongest. Shamanic drumming appears to be a systematic way of invoking experiences that are not only subconscious, but linked to a Gaian field at specific landscape sites. This assertion seems to some extent verifiable by experimental procedures; one of which I outline below.

A suggested procedure for collecting personal impressions during shamanic voyages was suggested by the experience of 5-10 individuals who were able to recall events after shamanic voyages (Harner 1980). At a location where the history of local events was well documented, a trance state of the 'middle world' type was induced by drumming for 20 minutes before recalling the participants. On returning to ordinary consciousness, they were asked not to discuss their experiences with others before completing a questionnaire. Statistical analysis of the results was incomplete due to inadequate information, but the location, events and entities encountered, appeared to be similar for all participants. In other words, potentially, we could investigate objectively the hypotheses of: a) a commonality of experience in the voyage, and b) some relevance of individual experiences to the known historical record of the locality.

\section{Integrating Science and personal belief systems?}

Saul Perlmutter, a Nobel prize winner in physics, expressed the idea (my translation from an Italian newspaper): 'Science is not the only way to address the world, and you need a complete arsenal of approaches and competences to do so... For centuries we have learned that not only is it very easy, but even very probable, that you start a discussion with the wrong ideas. This error may be global in our understanding of the physical world and human society, or inherent in the data we possess. We should proceed humbly, knowing that at the start we may be wrong in our interpretation, but eventually (our understanding) will improve'. 'Knowledge requires social cooperation, given that specialists lack a broad perspective, and generalists lack a depth of knowledge. Whether religious or not, we must keep in equilibrium the various ways of understanding the world, and use the instruments at our disposal in the best way possible'.

In seeking common ground between Science and the Spirit, it may help to view the problem from our species' original perspective on spiritual endeavours - shamanism. According to McKenna (1991), the practices and beliefs of 'primitive man' provide clues to our psychic capabilities; perhaps because it was under these primitive conditions that our sensory envelope was developed? This prompts the question: if our nervous systems evolved in the hunter-gatherer phase before literacy and logic, why such a complex neural structure? Language and social organization are usually considered responsible, but perhaps 'primitive man' was using the same neural equipment in a different way, with a wider range of sensory inputs? Since we have exhausted most paths to the rational investigation of the Spirit, revisiting old paradigms of knowing could be very profitable.

\section{A quick summary of the Energy Body, as viewed by vital energy practitioners}

Rather than dogmas, shamanic beliefs are practical techniques. For example: the vehicle for shamanic voyaging is 'The Energy Body': an ethereal structure of qi/prana energy that permeates and surrounds your 
physical body, but disappears from the physical plane on death. It consists of Meridians (energy channels), Chakras, (entry/exit points), and is wrapped in an Aura that extends out from your body. Chakras are whirlpools of qi that connect your physical to your astral body by a silver chord while you voyage to other dimensions or seek information elsewhere in time and space. Millennial experience shows that in order to cure some physical ailments, you must first cure the energy body. These and other vital energy components may be detected by most people after training in and practice. Phenomena associated with 'qi/'prana' are currently considered by conventional scientists as outside the scope of Science, and by default are 'imaginary', 'pathological', allucinations', or as a last resort, 'spiritual'! Perhaps it would be better to think of them as 'transdimensional phenomena'? The fact that they are not incorporated within the framework of conventional Science relates less to their validity, than to the radical changes in the theory of Science which would be required if they were adopted into 'reality'. I believe that eventually qi will be recognized as a trans-dimensional carrier of spiritual energy and information, and perhaps as a component of the zero-point field. I look to open-minded physicists such as Professor Tiller for clarity on the theoretical implications, but to me, the investigators will have to adopt a different mentality during their experiments: one that may be referred to by the words 'reverence', 'awe', as used in the past for recounting mystical experiences.

\section{Has the dominant chakra moved upwards in historical time?}

If the new field of investigation just postulated is spiritual, we may ask: why did miracles occur so long ago? The 'Theory of Chakras' seems to answer this question. Julian Jaynes (1976) contended that early city dwellers were not 'conscious' in our sense of 'self-aware'. He asserted that for the Ancient Greeks, their 'I' was located in the chest region, and was called 'the phrenes'. Other evidence that ancient peoples had more active lower chakras comes from testimony by the Sioux Indian seer, Black Elk: 'White men are crazy - they think with their heads, not with their hearts' (Neihardt 1972). According to Breasted (1964), still further back in time, the ancient Egyptian 'identity' was centred in the stomach region. Asian energy schools also stress development of the stomach chakra is the key to progress in martial arts. Taken together, these observations suggest that chakral dominance has migrated upwards in historical time from the abdomen where paranormal perceptions are more likely, to the brow chakra associated with logical/conscious thought. As a result of this change in dominance, it seems that we have neglected the perceptions available only through the lower chakras. Thus, on seeing supernatural entities, an Irish Seer noted that:" the physical eyes may be open or closed mystical beings in their own world and nature are never seen with the physical eyes". Mystical experiences seem less restricted for those with expanded auras and activated chakras. Pranic healers note that typically, one or more chakras are closed or inactive in modern people. Perversely, this may have some advantages, if we believe that the physical world is all there is. In fact, when making logical deductions from established facts, a low-moderate level of spiritual energy and inactive chakras are advisable - otherwise that non-logical process 'inspiration' (which changes our axioms) may intervene! (Inspiration is itself a word derived from that sharp inhalation we make when a convincing new idea arrives, apparently from nowhere)!

\section{Shamanism in pre-Christian Europe.}

Shamanism can be traced back beyond 60,000 years - i.e., almost certainly to before a few tribes of 'Homo sapiens' left Africa. Analysis of DNA markers records this as a possible date for key migrations of Homo sapiens, although other hominid species may have left Africa earlier. The first voyagers presumably carried with them some common beliefs and practices. Common elements now surviving in shamanism worldwide are the use of drumming/hallucinogens in trance voyaging to three non-ordinary destinations, the manipulation of vital energy, the use of animal guides or totems, the perception of especially energetic locations in the landscape, ritual rebirth/initiation ceremonies, and intimate relations with spirit forms and their ancestors. Current shamanic practice suggests that our distant ancestors used their energy bodies as '6th senses' and for trans-dimensional voyaging. Therefore, rather than seeking to discover something new, the priority search at this point in time is more for what we have lost in terms of personal capabilities, due to an overemphasis on rationality at the expense of intuition and visualization. The recent (re)discovery of remote viewing (see e.g., David Morehouse 2011), the confirmation of a degree of precognition, and the ability to dowse, were likely tools in the armoury of the shamans of ancient hunter-gatherers. All of these capabilities arguably resulted from a better understanding of the interaction between our subconscious and superconscious minds: for example, as used in Huna practice - an advanced form of shamanism practiced in Hawaii (Caddy 2013).

The extraordinary abundance of Stone Age monuments in Sardinia (Aresu 1995) and their location over underground water, suggests they were used for a range of practical, spiritual and curative purposes. They were ancient when Aristotle wrote of the ceremony of 'incubation' which in the classical world was associated with Sardinia. Persons seeking wisdom or a cure were buried in a 'giant's tomb' for up to 5 days. Practical applications of 'incubation' in creativity still abound today, used even by unbelievers! (see, e.g. Feynman 1997). 


\section{A physical theory compatible with shamanic beliefs}

The 'Gaia theory' of James Lovelock (1979) is based on mass planetary processes now in part verified by Science. The interdependence of such processes was intuitively seen by the Ancients to be controlled by the Earth Goddess, Gaia. This Animist belief in Nature as a planetary 'super-organism' is supported by the recent discovery of a common genetic heritage for the majority of organisms on the planet; making us 'organelles' of Gaia. Thus it is reasonable to see qi/prana as a means of communication between the living sub-units of Gaia. With few exceptions (see, e.g., Tiller et al. 2001), qi is not readily detectable by non-living devices, although anomalies in the performance of global random number generators described in meetings of the Society for Scientific Exploration, were found to coincide with catastrophic events (e.g. the Twin Towers event in New York). This perhaps implies that the shock wave of a multitude of persons reacting to the news on the Web, affected a physical process globally through Gaia?

Many seers describe the 'Aura of Gaia' as a stratum of heavy energy extending over and under the earth's surface which holds memories of past emotional events at a locality. My current sensibilities suggest we are 'embedded' in the aural field of the planet: a stratum of heavy or ground energy co-extensive with our personal auras, thus making us potentially sensitive to the wider range of phenomena available to our subconscious. Assuming that qi is an inextricable feature of living forms, a modern view of ground energy might consider relevant the recent discovery of archaeobacteria in rock down to $4 \mathrm{~km}$ below the planetary surface, where they make up a similar biomass to surface-dwelling organisms (Pedersen 2000). If they generate qi in the same way as surface organisms, an important research question might be to ask: do they contribute to the aural sheath around our planet?

Judging from modern experience with dowsing around ancient monuments erected in Sardinia prior to 1000 BC (Aresu 1995), it seems these were located over ground water, and their sites were chosen by water dowsing. The skills of geomancy, dowsing and Feng Shui must originally have been associated with Earth Mother belief systems, and the high ground energy of some pre-Christian sacred sites (springs, clearings and hill tops - Fig 1) was presumably reinforced by ceremonies. A scientific confirmation of the 'Physics of Ceremony' comes from the physicist Tiller (2001), who demonstrated that the 'imprinting' of localities and equipment by psychics leads to 'anomalous physics'.

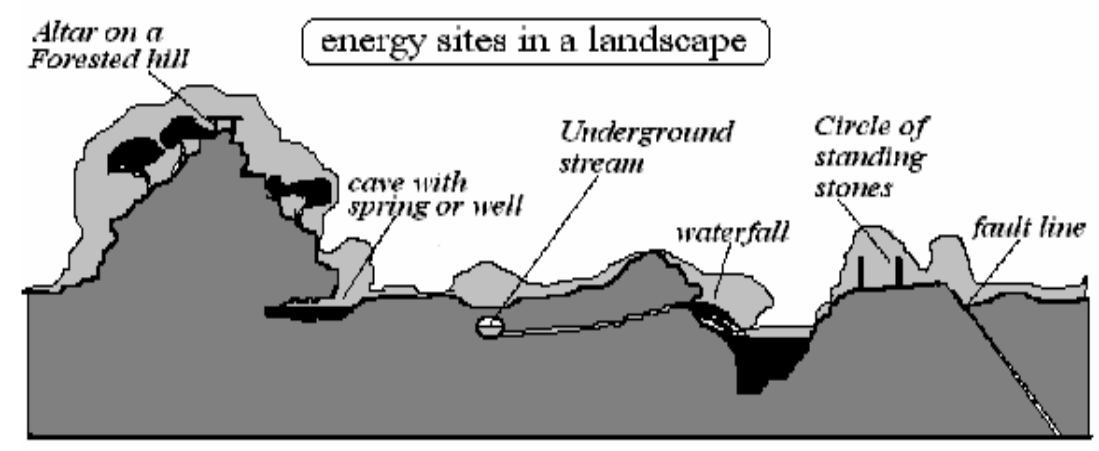

Fig 1. Dowsers experience landscape features as having different 'densities' of energy (from Caddy 2007).

\section{The spiritual realms of shamanism}

Shamanic voyaging (see Harner 1980) can be seen as a practical application of multiverse theory, in that it permits the participant to visit at least 3 distinct realms. These three destinations are recognized by shamanic societies around the world, and readily visited by non-practitioners, if guided by someone with shamanic experience:

1) The Lower World: A realm where spirit guides in the form of wild animals and tribal shamans may be encountered. In my personal experience of drumming for such groups, roughly 50\% of participants acquire an animal guide during Lower World ceremonies, and some report merging with their animal guide.

2) The Middle or 'Elemental' World: The energetic equivalent of the material world - often referred to as the Astral plane. This is the residence and place of encounter with nature spirits and those who have passed on. It may be possible to enquire from them on events that happened at a specific map location in the past - i.e. 'shamanic archaeology' is a possibility, as illustrated by the current field of Remote Viewing, (e.g. Morehouse 2011). Presumably dowsers access this realm unconsciously when seeking hidden resource or past events at a location? 
3) The Upper World: a realm of higher spiritual experience where advice may be obtained on spiritual matters - access is apparently by invitation and not available to all voyagers.

Astral voyaging and the Energy Body were known to our distant ancestors, and it is logical to review ancient practices when seeking to develop a new paradigm embracing Science and the Spirit. Voyaging is one of the oldest spiritual activities of our species and is available to almost everyone, and illustrates the persistence of information in Gaia's energy field. It appears that we are still 'hard wired' for access to the Upper, Middle (Astral) and Lower worlds of shamanic voyaging, which are 'constants' in shamanic thought and practice.

Rural belief systems surveyed in the 1900's (Evans Wentz 1977) suggest that the pre-Christian religion of the Celts was essentially shamanic. According to one Irish Seer: 'There are three great worlds we can see while we are in the body: the Earth world, the Mid world and the Heaven world'. As for Australian aboriginal beliefs, in Ireland, early Christianity coexisted with earlier 'pagan' beliefs (i.e., the two spiritual realities were 'superpositioned' or embedded together in the landscape). Other ancient European religions had similar geographical connotations - the Latins recognized high energy localities in a 'Cult of Places', each with its mythical entity in attendance (ref Giosuè Auletta - Historian).

Based on controlled experiments, the physicist William Tiller proposed that while we sense ourselves to be inside a realm of 4 dimensions, the universe contains at least 7 other dimensions hidden to us. I.e., the energy body is embedded in a multi-dimensional realm similarly to someone in a virtual reality suit, but we still retain occasional access to other dimensions. While voyaging in these 'parallel dimensions' you remain connected to your body by a 'silver chord' (Fig 2). This perhaps may be regarded as equivalent to the 'transdimensional 'worm holes' of theoretical physics envisaged by some cosmologists as potentially linking different 'States of Nature', which are separated by 'branes' or 'cosmic membranes'.
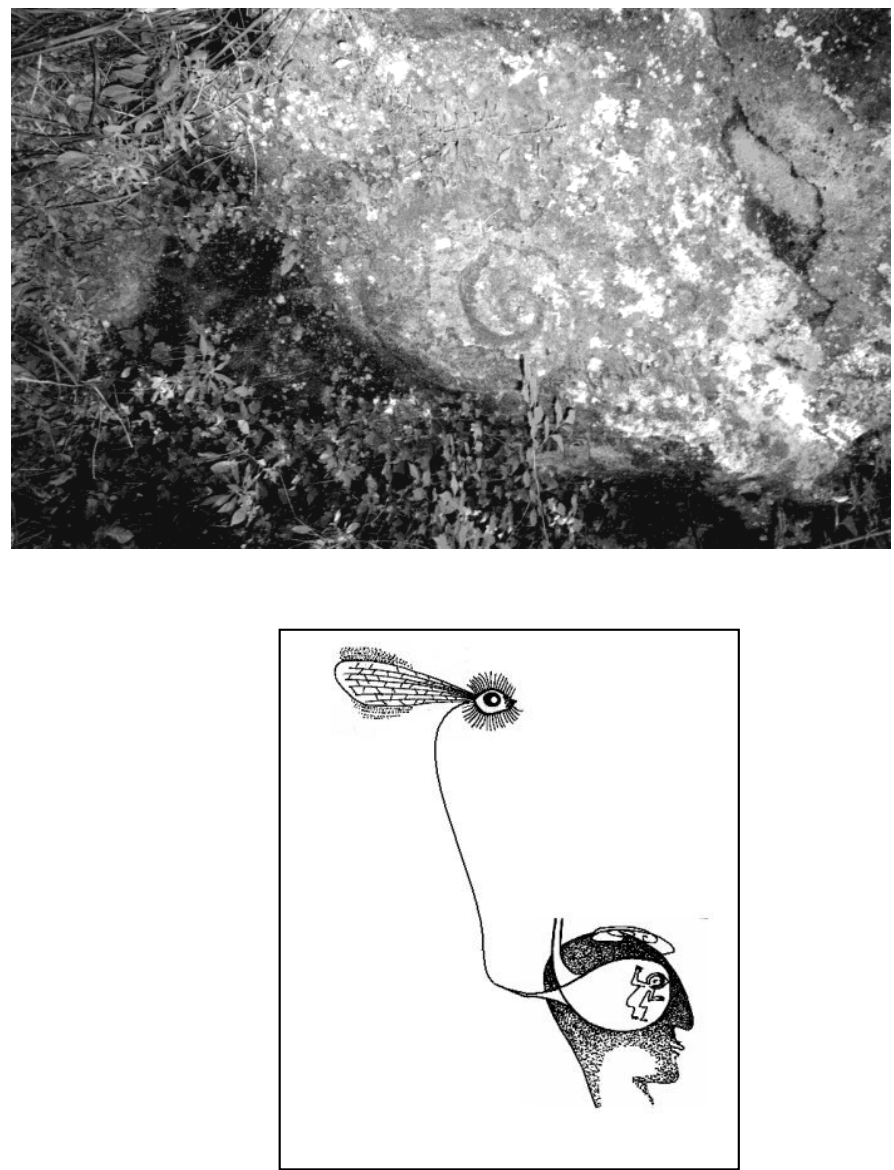

Fig 2: (left) A fanciful idea of our connection with the body by a silver chord while voyaging; (right) an engraved spiral at the entrance to an Etruscan 'sacred way'.

A 'tunnel' is traversed during visits to the Lower World. This has spirals on the inside wall, and those who have had pre-death experiences also report passing a tunnel with spirals. (According to Robert Graves, the preChristian Irish referred to dying as: 'Going to Spiral Castle'). 
A tunnel for access to other realms is paralleled by Buddhist, Australian aborigine, and Hopi 'ladders', 'mandalas' or 'dream catchers' - and of course chakras. These designs seem to induce mental voyaging in trance states. Such voyaging symbols appear to induce the growth of 'tubes' from the centre of a chakra to some other realm. Spirals are commonly encountered in rock art (e.g., Fig 2) and in early religious architecture, and such 'ground chakras' are circumstantial evidence that voyaging was commonly practiced in many early cultures. Spirals are also generated in the fractal mathematics of Mandelbrot (1977), and his 'fractional dimensions' generate spirals in boundary formulations that lead to models for different planes of reality.

\section{Evidence of esoteric knowledge and voyaging in pre-history}

Scattered evidence remains to be reinterpreted from a shamanic perspective that proto-Europeans had a knowledge of vital energy practices, even though much esoteric knowledge must have been lost in the 'Witch Trials' during the medieval Inquisition. Otzi', the 'Bronze Age' man found in 1991 in a glacier on the ItalianAustrian border, has tattoos on the same acupuncture points used by Chinese doctors for treating osteoarthritis. This suggests that our early European ancestors some 5000 years ago, were familiar with the theory of meridians (supposedly discovered in China 2-3000 years ago and re-imported to the West). A slate slab in the Grenada museum from 30-40,000 years ago (see Caddy 2007) shows a head with no sense organs, and lines diverging from the lower chakras; typical of a shaman preparing to voyage. This personage is in the 'HunterDiviner' posture described and tested by Gore (1995), who characterised it as an ancient method of clairvoyance: the 'destination' reached being specific to the posture used in meditation.

The accounts collected by Joan Halifax from shamans around the world in her classic book 'Shamanic Voices', show that apparently diverse 'primitive cultures' had similar capabilities and rituals. Archaeological evidence such as 'the shaman with the nose bleed' was portrayed by proto-bushmen in South Africa. Graham Hancock (2009) identified this shaman in rock engravings; he was bleeding from the nose following a tribal dance session. He is shown in another engraving merging with his animal guide, a large antelope - this can be identified as the transformed shaman since it is also bleeding from the nose! Hancock rejected the idea that human-animal transitional forms (therianthropes), common in rock art, represent humans dancing in animal costumes, since elements of animal anatomy are evident. Therianthropes are common in the paintings of Upper Palaeolithic caves in France and Spain from 20,000 - 40,000 years ago, suggesting that they portray voyages to the Lower World of shamanism; a conclusion reinforced by the similarity of early cave art with modern Lower World voyaging experience.

\section{Changing religious polarities: replacing the earth goddess by sky gods has its consequences!}

Apparently a reversal of the spiritual axis occurred in Europe at around the end of the New Stone Age, and this was associated with maternal deities losing their dominance to male counterparts in the belief systems currently existent.

In 'The White Lady', Robert Graves described how a male-dominated warrior society, the Achaeans, migrated from north of the Black Sea to replace the matriarchal societies of the Stone Age Mediterranean. He related this conquest to changes in the religious pantheon. Around this time, the formerly dominant earth goddesses of fertility under her various names (Gaia, Astarte, Venus, Aphrodite or Minerva), were relegated to a subordinate role in a male pantheon of Gods. Later, with the advent of Monotheism, a single male sky Deity took over. Graves speculated that prior to her overthrow, the Goddess of the Earth was the protective spirit our late Stone Age ancestors relied upon for good harvests and fertility. More or less contemporaneously, a reversal in the location of the afterlife occurred:

"After Christianity, the vulva of the land goddess" (a deep valley)" was redefined as the entrance to Hell" (Dames 1992). A below-ground afterlife was implied by an old Celtic tradition that the 'Faery Realm' (The Tir Na n'Og or Land of Bliss), was located under hills or lakes, as the Celtic Afterlife; accessed by chosen souls prior to reincarnation and rebirth. This was "a radiant archetype of the world" (Evans Wentz 1977), and another description of the Astral realm.

This description is in stark contrast to the below ground Greek Hades, and a similar location believed in by the Etruscans: a shadowy place where ghosts spent their time pining for life on the surface. This location resembles the interim destination of early Christians which is rarely mentioned nowadays - a 'posthumous purgatory' where $17^{\text {th }}$ Century Irish Catholics expected to spend time repenting their sins before moving upwards to Heaven. Its location (Evans Wentz 1977) was "near Limbo" (the destination for pure but unchristened souls and babies) "at the edge of the Pit beside the centre of the Earth..."Thus, monotheistic religions visualized underground 'real estate' as having deteriorated before arriving at Dante's Hell. With this reversal of sacred geometries, lost souls are now consigned to a location below ground which was previously occupied by heroes. An associated change that directly concerns us nowadays, is as already mentioned, that the credos of the Monotheistic 'sky' Gods pay scant respect to the spiritual value of the living world - which is still largely considered as 'raw material' by most monotheistic religions, given that only human beings have a soul. 
Fortunately, the recent encyclical of Pope Francis seems to be correcting this omission, but just how intelligent extraterrestrials fit into this scheme remains to be seen.

A related observation: Monotheistic religions ruled by male sky gods seemed to have arisen in low diversity steppe and desert habitats (e.g., Islam, Judaism, Zoroastrionism), but Animism/Pantheism and female deities came to dominance in high biodiversity forest habitats (e.g. Hinduism, the Balinese shamanic religion, Mayan beliefs). An interesting research question is: Do the religions that arise in an area reflect the diversity of the local ecosystem? - if so, why? Would we expect a desert religion to reflect the sacredness of the living world, as opposed to our dominance by the sun, moon, stars and Astrology/Astronomy? Prior to Monotheism, 'the Spirit' was associated with high energy locations in the natural world - 'Sources' were holy springs, caves, islands and woods. Nature is now seen by Materialism as without Spirit, and has become a 'Natural Resource'.

It is hard for us to interpret ancient monuments unless we call upon shamanic sources. For example, a belief that the deceased descend to the Earth Goddess on death appears illustrated by wall engravings from a troglodite dwelling in Sardinia, and by engraved dolmens (probably earlier than 2000 BC) discovered there fairly recently (Caddy 2006). In Tuscany, deep 'ceremonial ways' were cut into the soft sandstone rock by the Etruscans, linking the plateau with the bottom of deep gorges. At the start of one such 'Way' near Pitigliano, a spiral is cut into the gorge wall at the lower entrance, suggesting a 'voyaging' function (Fig 2). According to historical sources (Feo 2004), these 'Ways' were used for torchlight processions: perhaps the intention of the ceremony was to encounter the shades of deceased relatives in 'Hades' below ground? Modern voyagers 'riding the drum' to the Astral world may also encounter the deceased. Interpreting these locations may present difficulties for those who are believers in a 'sky religion', but in a recent Astral World voyage I drummed for in Sweden, five women in a group of nine, encountered relatives and friends who had passed on.

\section{Shamanic voyaging occurred in Europe, even in 'The Classical World'}

I live near Ardea, an ancient Latin town south of Rome. Its kings traced themselves back to Enaeus, the son of the king who fled here after the sacking of Troy by the ancient Greeks. A local historian, Giosuè Auletta (2004), wrote of 'spiritual voyages' at the 'Cave of the Faun - citing Virgil's 'Eneid': The king of the Latins was anxious about the future, and consulted the oracle of the Faun (my translation):

'People from all over Italy came to Lavinium to get replies to their questions. In the silence of the night they lay on the skins of sacrificed animals in front of the sacred cave from which issued a spring. In their sleep they entered into communication with the 'infernal' divinity through visions of strange phantoms and the babble of numerous voices'.

\section{Reincarnation and evolution}

According to Michael Dames, the Celts believed in rebirth from Gaia in a form compatible with individual immortality, taking into account evolutionary processes similar to those discovered by Science. For example, a source book, 'The Barddas' by Iolo Morganwg (1862-74), draws on ancient Celtic traditions in describing the evolution of physical and spiritual bodies:

"As a knowledge of physical existence is unfolded to it, the Monad or soul passes through every phase of material embodiment before it enters the human kingdom, where for the first time exercising free will in a physical body, it becomes responsible for all its acts.... The soul commences its course in the lowest wateranimalcule, and passes at death to other bodies of a superior order, successively, and in regular gradation, until it enters that of man".

The early Irish Church had adopted this belief in reincarnation from the earlier pagan Celtic creed until $553 \mathrm{AD}$ when the Council of Constantinople placed an 'anathema' on multiple rebirths (*). In a spirit of wider ecumenism, also compatible with Animism and Ecology, the American Indian prayer is 'For all our brethren...' This includes all animate and 'inanimate' components of the ecosystem within the term 'brethren'. In contrast, our special creation as a species envisaged in the Book of Genesis, allows no room for evolution. This still causes problems for those who read the Bible literally, and desperately search for an alternative to evolution that could explain the fossil record.

However, the Living World became Matter well before the birth of Christ. Socrates and Plato (around 400 BC) postulated a fundamental rift between Mind, and Matter plus Body. Mythos was replaced by Logos, and this set the scene for Science. As 'honorary pagans' the views of these philosophers were adopted by the Church, leading to the concept of 'Dualism'. This philosophy still persists today, postulating that "In each person good and evil battle within a cosmos in miniature”. This implies an equivalent split in the macrocosm between Heaven and Hell, and Good and Evil. Dualistic thought processes still permeate Science, which splits 
(*FOOTNOTE p24: Ian Stevenson who recently passed away, documented many cases suggestive of reincarnation, making this a difficult hypothesis to discount (see J. Sci. Explor. 22(1) dedicated to his work).

reality into ever-smaller specialities prior to investigation, such that scientists in different disciplines are often mutually incomprehensible, and few look at the whole picture. As remarked by Dames (1992), within Dualism two opposing forces play out their conflict in a soulless world (other than for human beings of course). Instead of being 'living manifestations of the Deity', clouds, moon, hills, vegetation etc, become 'Barriers blocking our view of an abstract Godhead'.

The aphorism: "History is (re)written by the victors" is true then, both for the material and spiritual worlds, and the ancient Romans, promoters of logical procedures and State bureaucracies were responsible for several examples of 'cultural cleansing' of shamanic thought. They wiped out our knowledge of their teachers the Etruscans, and in his 'Gallic Wars' Julius Caesar reported on his elimination of the oral Druidic culture of northern Europe. Cultural cleansing also recurred when the Inquisition aimed at demolishing pre-Christian mystical traditions. As a result, there is close to a vacuum in our knowledge of pre-Christian practices in Europe, except when recounted in distorted form by the victors. Nonetheless, several clues suggest that perceiving vital energy was commonplace in European prehistory, as well as manipulating earth and sky energies (see the 'Tao' of Classical China for apparent parallelism). Fragmentary evidence suggests our European ancestors were aware of the Energy Body, and used Astral Voyaging in a similar way to aborigines and bushmen nowadays. It only remains for us to reclaim useful elements of this ancient heritage.

\section{Some personal conclusions on 'vital energy' and voyaging}

- We are embedded in Gaia's energy field which varies geographically and temporally in intensity.

- As a result, the boundaries of an individual's memory are uncertain and may not stop at the skin - Gaia's field may act as an information storage medium.

- Fault lines, ceremonies and past traumas may induce local 'hot/cold energy spots' in the landscape.

- Dowsing probably accesses information in Gaia's field through the aura.

- 'Objective observations' on others in a qi field are impossible (the 'Observer effect' of quantum science prevails, and makes the observer part of the equation).

My experience suggests that Astral voyaging at historic sites could help retrieve lost knowledge by what can be called 'Shamanic Archaeology'. This viewpoint also suggests that pre-classical records and sites are best interpreted in the light of earlier shamanic practices, rather than by looking backwards from monotheism or scientific materialism. Notable here is that archaic elements encountered by modern 'voyagers' are reminiscent of the earliest human 'rock art'. Subjective experience suggests that the 'voyage' is not just a psychological phenomenon, but a visit by the spirit to non-ordinary planes of reality. Experts in voyaging (e.g. Bruce 1999) suggest that by passing out through the centre of a chakra, the spirit body or 'soul' remains attached to the physical body by a silver chord.

Other observations and hypotheses that are worth considering, if we take our shamanic ancestry seriously, are:

- Most people are capable of 'flight' while 'riding the drum'.

-The locations and persons/entities encountered and the information obtained, is often new and surprising.

- Often, there is a transmission of emotionally important information to the voyager.

- This may involve 'communication' with deceased persons.

- In 'voyages', non-ordinary hearing (despite the drum beats), sight, smell, and touch may be activated.

- Events that occurred at the drumming site in the past may be revisited.

- Not everyone can make upper world voyages, which seem to be 'by invitation'.

- The animal guides to the Lower World usually remain the same on successive voyages.

- The animal guide often seeks to take the voyager to some distant point it believes important.

- It helps to enter the voyage with a question or objective in mind.

- The 'motive force' for voyaging and other shamanic exercises is 'Intent'.

\section{How does a shamanic perspective help us in reconciling science and spirituality?}

While it may have been inevitable that humans eventually sought the divine in the heavens, a spirituality soundly based on the living world around us and beneath our feet needs to re-emerge. This has direct relevance to the conservation movement, and to defining appropriate ethical behaviour within our closed terrestrial ecosystem. The original view of the Earth which shamanism was based on, namely as a living being made up of all the organisms on the planet, is fortunately coming back into favour. However, serious damage has been done by suppressing our commonality of origin with other living forms. Even if mistaken, reviving the 
shamanic viewpoint promotes appropriate ecological actions. In both the long and short run, only by seeing the Earth as a 'sacred relict' (quote from a Russian astronaut) can we hope to preserve the living systems we and our descendants depend upon for our existence.

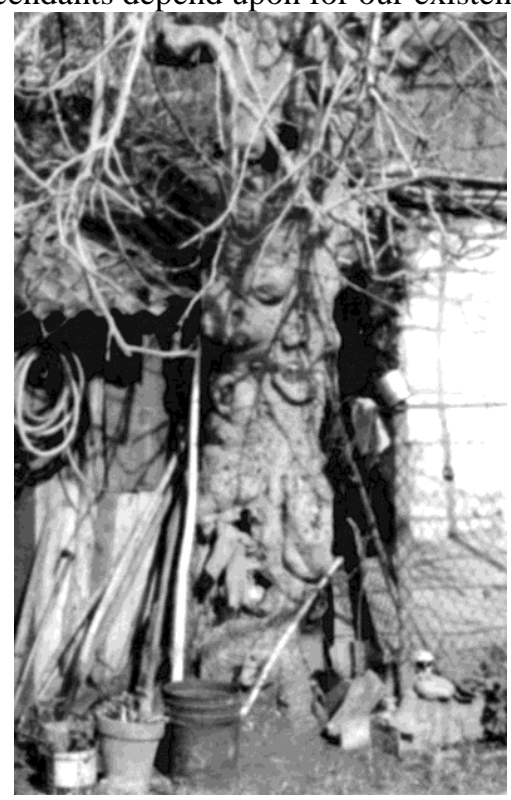

\section{CONCLUSIONS}

I believe that ancient belief systems contained realistic components that probably stemmed from aeons-long observation of the world by our ancestors while in hunter/gatherer mode, before the divide between physical knowledge and spirituality became crystallized. Repeating ancient practices may allow us to gain an insight into their belief systems. Shamanic voyaging will help interpret pre-literate images - but more importantly, casts light on some non-ordinary aspects of reality. I believe that the copious material cited in the book by Evans Wentz points to a continuity of perception and a long tradition of belief and practice in contacts with otherworldly entities and visits to other planes of being by our ancestors. There is often a landscape connection to these experiences.

Three possible explanations are:

1) These events simply represent the persistence of psychic memory traces stored in the standing waves of chi generated around specific landscape features;

2) They are memetic structures left in Gaia's aura at points in the landscape by repeated past ceremonies;

3) They are memories of actual visits to other-wordly planes of being, or encounters with entities from other worlds or planes. Which of these ideas is most plausible is not clear to the author, but from personal experience it is difficult to simply dismiss ancient and widespread traditions of contacts with intelligent, non-human entities. It also seems a reasonable hypothesis that the 'fairy lore' of Celtic countries (and elsewhere) belongs in the same category as more recent 'sightings' of aliens and UFOs. Using persons with paranormal capabilities to investigate mysterious events on their location of occurrence offers the possibility of a better understanding nonordinary phenomenon not yet explained by science or religion.

A final comment: A substantial component of our ancient spiritual traditions, and stories of mystical entities, seem to reflect our unacknowledged history of early contacts with extra-terrestrial visitors. If so, it would seem that developing greater sensitivity to qi phenomena will ease eventual mutual comprehension and co-existence with intelligent entities coming here from elsewhere in the universe.

\section{REFERENCES}

[1] Aresu, M. (1995) Uomoterra: testimonianza di Energia ritrovata. Ago e Filo (Palau, Sardinia).

[2] Auletta, G. (2004). Lazio Virgiliano. Data Ufficio Editore.

[3] Breasted, J. H. (1964). A History of Egypt (1905). 1964 Edition; Bantam Books, New York.

[4] Bruce, R. (1999). Astral dynamics: A new approach to Out-Of-Body Experience. Hampton Roads Publishing Company.

[5] Caddy, J.F. (2007). A Return to Subjectivity. Trafford Press.

[6] Caddy, J.F. (2007). Shamanic Archaeology. Paranormal Magazine. Oct 2006. 
[7] Caddy, J.F. (MS; 2007). Using dowsing to rank the energy of the emotional and rational vocabulary the results of a training course.

[8] Caddy, J.F. (2011). Hidden in the words: a meaning undetected. Authorhouse, 96p.

[9] Caddy, J.F. (2013). The Huna philosophy and 'Objective Observations' Syntropy 2013 (2): 145-169.

[10] Chatwin, B. (1988). The Songlines. Penguin, 304 p.

[11] Dames, M. (1992). Mythic Ireland. Thames and Hudson, N.Y.

[12] Clark, G. and S. Piggott. (1965). Prehistoric societies. Pelican books.

[13] Coleman (quoted in) Dames, M. (1992). Mythic Ireland. Thames and Hudson.

[14] Eaglefeather, K. A. (1995). A Toltec path. Hampton Roads Publishing Company, Eagle Dynamics, Inc. $273 p$.

[15] Evans Wentz, W.Y.E.(1977). The fairy faith in Celtic countries. Colin Smythe Ltd.

[16] Feo, G. (2004). Le vie cave Etrusche. Laurum Editrice.

[17] Feynman, R.P. (1997). Surely You're Joking, Mr. Feynman! (Adventures of a Curious Character) Paperback - April 17, 1997.(W.W. Norton and Co).

[18] Gore, B. (1995). Ecstatic body postures. Bear and Co Publishing, Santa Fe, New Mexico.

[19] Graves, R. (1961). The White Goddess. Faber and Faber.

[20] Greer, S.M. (1999). Extraterrestrial contact: the evidence and implications. Crossing Point Inc.

[21] Greer, S.M. (2006). Hidden truth: forbidden knowledge. Crossing Point Inc.

[22] Halifax, J. (1979). Shamanic voices. Compass/Penguin.

[23] Hancock, G. (2005). Supernatural. Arrow Books.

[24] Harner, M. (1980). The way of the shaman. Bantam New Age books.

[25] Jaynes, J. (1976). The origin of consciousness in the breakdown of the bicameral mind. Houghton Mifflin Co., Boston.

[26] Kuhn, T. (1970). The structure of scientific revolutions. University of Chicago Press, Chicago.

[27] Lovelock, J. (1979): Gaia. A New Look at Life on Earth, Oxford University Press.

[28] McLuhan, M. (1994).Understanding Media: The Extensions of Man. $1^{\text {st }}$ MIT Press.

[29] Mandelbrot, B.B. (1977). The Fractal geometry of Nature. W.H. Freeman and Co.

[30] McKenna, T. (1991). The Archaic Revival. HarperSanFrancisco.

[31] Morehouse, D. (2011). Remote Viewing. Sounds True,Inc. Boulder. Co. 395p.

[32] Motoyama, H. (1995). Theories of the Chakras. Quest Books.

[33] Neihardt, J.G. (1972). Black Elk speaks. University of Nebraska Press, 298p.

[34] Pedersen, K. (2000). Exploration of deep intraterrestrial microbial life: current perspectives. Microbiology Letters, Volume 185, Issue 1, pp 9-16.

[35] Peitgen, H.-O. and P.H. Richter. (1986). The Beauty of Fractals. Springer-Verlag.

[36] Strassman, R. (2001). DMT: The spirit Molecule. Park Street Press.

[37] Sutcliffe, J.F. (2003). Mankind at the crossroads. Arthur Stockwell Ltd., 80p.

[38] Tiller, W., W.E. Dibble and M. J. Kohane. (2001). Conscious acts of creation. Pavior/Quality Books.

[39] Watkins, A. (1925). The old straight track, its mounds, beacons, moats, sites and mark stones. Garnstone Press, London. 